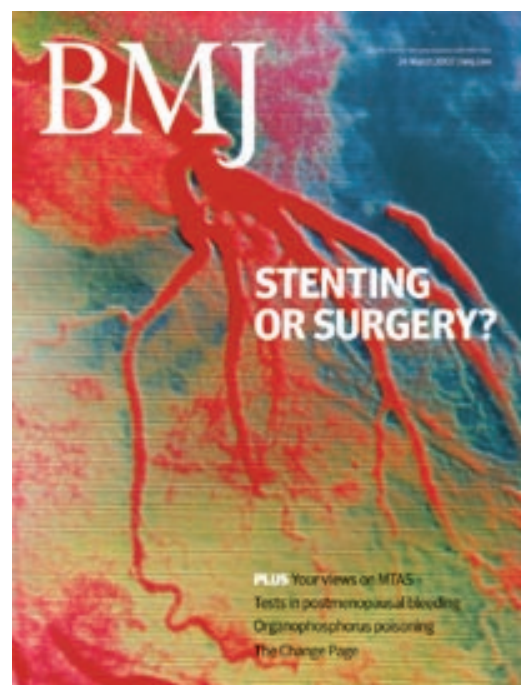

\section{TO STENT OR NOT TO STENT?}

\section{A sterile debate}

Did the recent $B M J$ articles improve the evidence for the superiority of coronary artery bypass grafting $(\mathrm{CABG})$ over percutaneous coronary intervention (PCI) as claimed $?^{1-3}$ In 2006 the featured minimally invasive direct coronary artery bypass graft (MIDCAB) operation for isolated left anterior descending disease accounted for less than $0.5 \%$ of $24000 \mathrm{CABG}$ procedures in the United Kingdom. ${ }^{12}$ Equally the economic arguments apply to practice and hospital costs 10 years ago, ${ }^{3}$ when PCI strategies were limited, first generation stents were more expensive, and 2-3 days in hospital were considered necessary for safe practice. However, in a current contest between the two procedures 3-5 PCIs more reasonably equate to one $\mathrm{CABG}$.

Currently CABG achieves lower reintervention rates and marginally better survival in multivessel disease with a left main stem lesion. Diabetic patients with diffuse three vessel disease fare better with CABG. Some who are unsuitable for PCI are also poor $\mathrm{CABG}$ candidates because of calcified vessels.

Acute coronary syndromes now account for $50 \%$ of PCI practice. Many patients have extensive comorbidity and multivessel disease. They are unlikely to be offered urgent $\mathrm{CABG}$ as raised troponin concentration is a relative contraindication.
Bridgewater et al suggest counterintuitively that media reporting of CABG mortality statistics (since 2001) has not caused risk averse behaviour in surgeons. ${ }^{4}$ However, data reporting practices changed at this time. $\mathrm{CABG}$ mortality fell, as did the number of cases with left ventricular ejection fraction $<30 \%$ (only $5.5 \%$ ). Without a "surgical breakthrough" this implies modification of patient selection.

The relative merits of PCI and CABG in complex multivessel disease have been addressed in a trial which recently completed recruitment of 1800 patients. ${ }^{5}$ This initiative will provide clear guidance to override the use of selected data in support of one approach over the other. Even so, many less sanguine patients will still choose one or more PCIs first, knowing that CABG is possible if symptoms return.

In summary, $\mathrm{PCI}$ and $\mathrm{CABG}$ are complementary, not competitive. PCI is preferred for multifocal discrete disease and CABG for diffuse disease with chronic occlusions. Patient choice must now be included in the evidence base.

Stephen Westaby professor, department of cardiac surgery John Radcliffe Hospital, Oxford OX3 9DU swestaby@AHF.org.uk

Keith Channon professor of cardiovascular medicine, department of cardiology

Adrian Banning consultant, department of cardiology

Competing interests: The authors, a cardiac surgeon and two cardiologists, are SYNTAX investigators and benefit from private practice in myocardial revascularisation.

1 Aziz O, Rao C, Panesar SS, Jones C, Morris S, Darzi A, et al. Meta analysis of minimally invasive internal thoracic artery bypass versus percutaneous revascularisation for isolated lesions of the left anterior descending artery. BMJ 2007;334:617-21. (24 March.)

2 Rao C, Aziz O, Panesar SS, Jons C, Morris S, Darzi A, et al. Cost effectiveness analysis of minimally invasive internal thoracic artery bypass versus percutaneous revascularisation for isolated lesions of the left anterior descending artery. BMJ 2007;334:621-4. (24 March.)

3 Griffin SC, Barber JA, Manca A, Sculpher MJ, Thomson SG, Buxton MJ, et al. Cost effectiveness of clinically appropriate decisions on alternative treatments fo angina pectoris: prospective observational study. BMJ 2007;334:624-8. (24 March.)

4 Bridgewater B, Grayson A, Brooks N, Grotte G, Fabri $\mathrm{B}, \mathrm{Au}$ J, et al. Has the publication of cardiac surgery outcome data been associated with changes in practice in Northwest England? An analysis of 25,730 patients undergoing CABG surgery under 30 surgeons over 8 years. Heart May 2007; doi 10.11.36/hrt 2006.106393

5 Ong AT, Serruys PW, Mohr FW, Morice MC, Kappetein AP, Holmes DR Jr, et al. The SYNergy between percutaneous coronary intervention with TAXus and cardiac surgery (SYNTAX) study: design, rationale, and run-in phase. $A m$ Heart /2006;151:1194-204.

\section{eGFR AND CHRONIC KIDNEY DISEASE}

\section{Time to move forward}

Giles and Fitzmaurice's arguments are designed to persuade $B M J$ readers that reporting estimated glomerular filtration rate (eGFR) has introduced a screening programme by the back door, will pressurise specialist services, and cause unnecessary anxiety and harm to patients in terms of getting life insurance and receiving inappropriate treatment. ${ }^{1}$

The marked increase in referrals of patients with newly diagnosed chronic kidney disease is likely to be temporary due to referral of patients with prevalent disease. UK guidelines ensure that only patients who will receive added value from a specialist opinion are referred ${ }^{2}$ : most can safely and more efficiently be managed in primary care. ${ }^{3}$ Most patients diagnosed as having chronic kidney disease as a result of eGFR reporting are older, few of whom will take out new life insurance. Angiotensin converting enzyme inhibitors are indicated only in the presence of hypertension (in the quality and outcomes framework (QOF)), in keeping with current NICE guidance.

Reporting eGFR has improved the clinical interpretation of an established test (serum creatinine). ${ }^{4} \mathrm{~A}$ main aim was to reduce the morbidity and mortality associated with late referral to nephrology services of patients with advanced disease. ${ }^{5}$ The indications for testing serum creatinine concentration have not been changed by eGFR reporting.

The simplified MDRD (modification of diet in renal disease) equation does not provide a perfect estimate of glomerular filtration rate. Improved assay precision, specificity, and standardisation will help. Currently, harmonisation through the United Kingdom National External Quality Assessment Scheme achieves betweenlaboratory agreement (coefficient of variation) of around $6 \%$ at rates around $60 \mathrm{ml} / \mathrm{min} /$ $1.73 \mathrm{~m}^{2}$. As the authors acknowledge, the equation is useful to identify stage 3-5 disease, as required by the QOF.

CR V Tomson past chair, Joint Specialty Committee on Renal Medicine of the Renal Association and the Royal College of Physicians, Renal Medicine, Southmead Hospital, Bristol BS10 5NB 
EJ Lamb consultant clinical scientist, Clinical Biochemistry, East Kent Hospitals NHS Trust, Kent and Canterbury Hospital, Canterbury CT13NG

edmund.lamb@ekht.nhs.uk

K Griffith general practitioner, University Health Centre, York University, York Y010 5DD

D O’Donoghue national clinical director of kidney care, Department of Nephrology, Salford Royal Hospital NHS Trust, Hope Hospital, Salford M6 8HD

J Feehally immediate past president, Renal Association John Walls Renal Unit, Leicester General Hospital,

Leicester LE5 4 PW

Competing interests: None declared.

1 Giles PD, Fitzmaurice DA. Formula estimation of glomerular filtration rate: have we gone wrong? BMJ 2007;334:1198-200. (9 June.)

2 Joint Specialty Committee on Renal Medicine of the Royal College of Physicians and the Renal Association, and the Royal College of General Practitioners. Chronic kidney disease in adults: UK guidelines for identification, management and referral. London: Royal College of Physicians, 2006.

3 Mitra PK, Tasker PR, Ell MS. Chronic kidney disease. BM 2007;334:1273. (16 June.)

4 Wyatt C, Konduri V, Eng J, Rohatgi R. Reporting of estimated GFR in the primary care clinic. Am J Kidney Dis 2007;49:634-41

5 Roderick P, Jones C, Tomson C, Mason J. Late referral for dialysis: improving the management of chronic renal disease. Q/ Med 2002;95:363-70.

\section{USING HEALTHCARE DATA}

\section{Security protection is needed when using USB sticks}

Current working hours for junior staff mean that effective patient handovers are critical. Handwritten sheets have been superseded by electronic storage of patient data available to the clinical team. ${ }^{1}$

Universal serial bus (USB) sticks have greater security risks than other media due to their size, storage capacity, and convenience. Trust policy states that confidential data should be stored on 128-bit encrypted USB sticks, with "if found" labels on them, and be used solely on the trust's computers.

Criminals now recognise the value of personal data in the growing identity theft market. Recently confidential patient data held on an unprotected USB stick were stolen. The trust had to inform the patient and face liability for distress or damage caused along with public condemnation (D Terry, personal communication, July 2007). In addition, clinical information is lost permanently, and there is the financial cost of replacing equipment.

I asked 50 junior doctors about their electronic storage of patient data. Thirty six of them stored patient data electronically, 20 using a USB stick, three a floppy disk, and 13 a hospital computer hard drive. None of the 20 USB sticks had 128-bit encryption, and only three had password protection (still insufficient for the trust's requirements). Four doctors used the same device on their personal computer(s), two of which had patient data stored on them.

Cognisant of the sensitive patient information held electronically, the Caldicott and data protection adviser has recommended enhanced USB stick security protection to the trust, with mandatory password protection. The trust intends to supply 128-bit secured USB sticks for medical firms to use on wards, and an extensive communications programme will seek to raise awareness and promote compliance.

Matthew Daunt F1 doctor, Queen's Medical Centre, Nottingham University Hospitals Trust, Nottingham NG7 2UH mattdaunt@doctors.org.uk

Competing interests: None declared.

1 Wade $D$. Ethics of collecting and using healthcare data. BM/ 2007;334:1330-1. (30 June.)

\section{MANAGING SMOKING CESSATION}

\section{Article skips over weaknesses of nicotine replacement}

Aveyard and West state that the Allen Carr Easyway method showed abstinence rates similar to those expected from behavioural support alone, quoting McRobbie et al instead of the two cohort studies mentioned. ${ }^{12}$ They omit two studies which found persistent abstinence in half of the cohort, in some of which nicotine replacement had failed. ${ }^{3}{ }^{4}$ Even more serious is the omission of the risks of nicotine replacement to the fetus which were reviewed recently. ${ }^{5}$

Manfred Neuberger professor

Department of Preventive Medicine, Medical University of

Vienna, Kinderspitalgasse 15, A-1095 Vienna, Austria

manfred.neuberger@meduniwien.ac.at

Competing interests: None declared.

1 Aveyard P, West R. Managing smoking cessation. BM] 2007;335:37-41. (7 July.)

2 McRobbie H, Hajek P, Bullen C, Feigin V. Rapid review of non-NHS treatments for smoking cessation. 2 Feb 2007. http://guidance.nice.org.uk/page \%20aspx?0=404436

3 Hutter H, Moshammer H, Neuberger M. Smoking cessation at the workplace: one year success of short seminars. IntArch Occup Environ Health 2006;79:42-8.

4 Moshammer $\mathrm{H}$, Neuberger $\mathrm{M}$. Long term success of short smoking cessation seminars supported by occupational health care. Addict Behav 2007;32:1486-93.

5 Ginzel KH, Maritz GS, Marks DF, Neuberger M, Pauly JR, Polito JR, et al. Nicotine for the fetus, the infant and the adolescent? J Health Psychol 2007;12:215-24.

\section{SCIATICA}

\section{An archaic term}

In their clinical review Koes et al use the entirely non-evidence-based term "sciatica." From the Greek, it literally means hip pain. In English, the Oxford English Dictionary gives precedent to a quote from Shakespeare's Timon of Athens (act IV, scene I), where sciatica is a curse placed on the senators. None of this is a good basis for current usage, which is supposed to describe nerve root or radicular pain, as the authors note but do not discuss.

The problem is that patients with back pain may also have referred pain, a phenomenon first pointed out by Kellgren over 60 years ago. ${ }^{2}$ Clinicians are not good at making this distinction, but they should try. This issue takes on greater importance when studying the evidence base where often this distinction is not made. Persistent use of the archaic word sciatica in the clinical setting is not in the best interests of people with a miserable and disabling condition. It remains an effective curse, but English terms such as nerve root pain or radicular pain better describe the clinical problem.

Jeremy C T Fairbank consultant orthopaedic surgeon Nuffield Orthopaedic Centre, Oxford OX3 7LD jeremy.fairbank@ndos.ox.ac.uk

Competing interests: None declared

1 Koes BW, van Tulder MW, Peul WC. Diagnosis and treatment of sciatica. BM/ 2007;334:1313-7. (23 June.) 2 Kellgren J. Sciatica. Lancet 1941;i:561-4.

\section{ATTENDING PATIENTS' FUNERALS}

\section{We can always care}

When our son died of cancer last year at the age of 25, a number of his doctors and nurses came to his funeral. ${ }^{1}$ We were not able to talk to them at the time, but we knew that they had been there as they filled in cards which the funeral director provides. We have had contact with one or two of them since, and the shared experience was of tremendous importance. It meant a lot to us that they had taken time out of their busy schedule to come. For us it was an important mark of respect for our son. It showed that they cared and was part of a long healing process.

As a community paediatrician I (RT) have tried wherever possible to attend the funerals of disabled children under my care. I have usually grown to know the families well. The untimely death of a child or young adult is devastating, and families have always seemed to appreciate my presence. We cannot always cure but we can always care. My personal experience has reinforced this feeling a hundredfold.

Ros Thorburn consultant community paediatrician ros.thorburn@doctors.org.uk

Martin Roland professor of general practice

Warrington WA51TP

Competing interests: None declared.

1 Arroll B, Falloon K. Should doctors go to patients' funerals? $B M /$ 2007;334:1322. (23 June.) 